\title{
An Investigation Study on the Role and Performance Ability of Physical Therapists in the Community Care System for Elderly
}

\author{
Sang-Yeol Lee', Su-Hong Choi ${ }^{2}$ Kyung-Jin $\mathrm{Ha}^{3}$, Min-Hyung Rhee ${ }^{2}$ \\ 'Department of Physical Therapy, Kyungsung University, Busan, Korea; ${ }^{2}$ Department of Rehabilitation Medicine, Pusan National University Hospital, \\ Busan; ${ }^{3}$ Department of rehabilitation therapy center Dong-a University Hospital, Busan, Korea
}

Purpose: A survey was conducted to investigate the role, priority, and awareness of physical therapists in the community care system for the elderly.

Methods: Nine hundred ninety-three physical therapists were invited to an online survey from 1st to 30th June 2020.

Results: While the awareness of physical therapists for the community care system for the elderly was found to be low, the role priority and performance ability were found to be high. Fall training scored the highest for the job duties of physical therapists, and functional training scored the highest for the performance ability of physical therapists. For the role priority by the education status regarding the community care system, the participants who received the education program showed higher scores in the performance ability than those who did not. For the role priority and performance ability according to the education levels, higher education levels resulted in higher scores in both outcomes. Regarding the clinical experience, low scores were found in the participants with less than five years of experience.

Conclusion: Physical therapy establishes itself as an essential area of expertise in the community care system for the elderly. Therefore, these results can be utilized in developing a model for Korean community care for the elderly.

Keywords: Awareness, Community care, Physical therapy, Role priority

\section{서 론}

한국의 보건복지부는 2026년 초고령 사회를 앞두고 커뮤니티케어의 보편적 제공을 위해 2018년 3월 노인에 대한 돌봄의 체계를 병·의원 에서 대상자의 삶의 공간으로 변화시키기 위해 커뮤니티케어를 중심 으로 전환한다고 발표하였다. 이에 따르면 포용적 복지 영역 내에 건 강·의료 보장과 함께 방문 의료, 발달 장애인 돌봄 보장, 주거 지원 등 의 커뮤니티케어에 대한 중요성을 강조하고 있다. 커뮤니티케어는 기 본적으로 대상자가 살던 곳에서 개개인의 욕구에 맞는 서비스를 누 리고 지역사회와 함께 어울려 살아갈 수 있는 주거, 보건의료, 요양, 돌봄, 독립 생활의 지원이 통합적으로 확보되는 지역 주도형 사회서 비스 정책이다. ${ }^{1}$

세계적으로 연속적인 의료 서비스 제공을 위해 병원 중심에서 지 역 사회 중심으로의 전환을 시도하고 있다. 일본은 2000년 개호 보험 을 도입하여 의료와 개호(간병) 중심의 서비스를 시작하였으며, 2025

Received Aug 6, 2020 Revised Aug 17, 2020

Accepted Aug 28, 2020

Corresponding author Min-Hyung Rhee

E-mail minhyung@gmail.com
년을 목표로 노인이 재활과 돌봄이 필요한 중증 질환을 가지고 있으 며 독거일지라도 기존의 생활환경에서 연속적인 의료 서비스를 제공 받도록 하기 위해 2015년 이를 지역사회를 중심으로 한 재활서비스 로 전환하였다. 독일의 장기요양제도에서는 2013년 수발 보호법 개정 을 통하여 치매 노인에게 재가 급여를 받을 수 있도록 확대하였다. 세 계의 복지선진국에서도 1990년대에 들어 케어를 위한 전문적 인력 (care management)인 물리치료사, 작업치료사, 정신 간호사, 사회사업 가 등을 통한 지방정부의 역할을 강조하는 돌봄 서비스를 제공하고 있다. ${ }^{2}$ 이와 같이 많은 복지 선진국에서 장기요양 서비스에서의 커뮤 니티케어의 중요성을 강조하고 있으며, 이를 대상자의 특성과 거주 환 경 등을 고려한 맞춤형 케어를 위해 탈중앙화 정책을 시도하고 있다. 또한 이러한 노인 케어의 중심을 지역사회로의 이전은 접근성과 전달 체계의 효율성 및 행정적 대응에 있어 많은 장점을 가지고 있다.3.4

세계적인 추세에 따라 $\mathrm{OECD}$ 선진국의 수준으로 장기요양보험 수급 자를 확대할 경우, 한국은 2025년 수급자의 수가 120 만명에 달할 것으 
로 예상된다. 이는 커뮤니티케어 서비스의 대상 노인의 수가 급증하는 것을 의미한다. 보건복지부는 폭발적으로 늘어나는 노인장기요양보험 수급자를 위해 병원의 서비스 전문화와합리적 이용 유도 및 지역사회 자율형 커뮤니티케어 서비스 연계 구축, 전문 인력 양성 및 기술적 마련 을 제시하고 있다. ${ }^{1} \mathrm{WHO}$ 는 성공적인 커뮤니티케어의 정착을 위해 다 양성이확보된 전문 인력과지역사회의 협조가 필요하다고 강조한다.

물리치료사는 지역사회와 전문 단체에서 의료서비스 제공 시스템 에서의 필수 참여자이며 재활서비스에서의 중요한 역할을 하고 지역 사회를 위해 건강 및 건강 증진 및 유지와 예방에 관련된 프로그램을 구성하는 역할을 한다. 또한 물리치료사는 오래전부터 지역사회의 건강을 유지하고 질병에 대한 예방과 치료를 위해 많은 국가들에서 그 역할을 수행하고 있으며 사회적인 필요성이 강조되고 있다. ${ }^{4}$

하지만 장기요양보험에서 노인 삶의 질 증대를 위하여 일상생활, 신 체활동지원이 주를 이루고 있음에도 불구하고 커뮤니티케어에서의 재활 전문가인 물리치료사분포가 매우 적은 실정이다. 이는 커뮤니티 케어에서의 물리치료 항목 미흡, 보건소 방문사업에서의 물리치료사 의 부족, 방문물리치료에 대한 홍보와 연구 부족 등이 이유이다. 따라 서 커뮤니티케어 제도 내에서 물리치료사의 역할이 안착되고 보다 넓 은 서비스를 제공하기 위해서는 보다다양한 방향의 연구가 필요하다.

본 연구는 정부의 노인 커뮤니티케어 정책에 따라 물리치료사의 전문성 강화를 대비하고 물리치료사의 본 제도에 대한 인식을 조사 하고 물리치료사의 업무 중요도에 대한 인식을 알아보기 위하여 실 시되었으며, 본 연구의 결과가 노인 커뮤니티케어 제도에서의 물리치 료사 업무에 대한 방향 제시에 근거자료로 제공될 것으로 생각된다.

\section{연구 방법}

\section{1. 연구 대상 및 자료 수집 방법}

본 연구는 2020년 6월 1 일부터 30 일까지 1달간 자발적으로 연구에 참 여한 전국 938 명의 물리치료사를 대상으로 실시하였다. 자료 수집 전 연구 대상자의 권리, 연구의 목적 및 자료 사용 용도에 대한 정보를 설 명문으로 제공하였으며, 본 연구 참여에 동의한 대상자만 설문에 응 답할 수 있는 선택권을 대상자에게 주었다. 본 연구는 온라인 설문을 통해 조사하였으며, 본 설문의 내용과 참여 방법은 물리치료 관련 학 회와 대한물리치료사협회의 홈페이지를 통하여 제공하였다. 설문지 전체 문항 중 하나의 답변이라도 기록이 빠진 설문은 불성실 답변으 로 정의하고, 설문지 분석에서 제외하였다. 설문에 참여한 전체 대상 자 938 명 중 불성실 답변 118 명의 데이터를 제외하고, 총 820 명의 데이 터를 분석에 사용하였다. 설문에 참여한 대상자의 일반적인 분포와 특성은 다음과 같다(Table 1).
Table 1. Characteristics of participations

\begin{tabular}{|c|c|c|c|}
\hline & Characteristics & Participants (N) & $\%$ \\
\hline \multirow[t]{2}{*}{ Gender } & Male & 498 & 60.7 \\
\hline & Female & 322 & 39.3 \\
\hline \multirow[t]{5}{*}{ Age } & $20 \mathrm{~s}$ & 256 & 31.2 \\
\hline & $30 \mathrm{~s}$ & 294 & 35.9 \\
\hline & $40 \mathrm{~s}$ & 191 & 23.3 \\
\hline & $50 \mathrm{~s}$ & 72 & 8.8 \\
\hline & over 60 & 7 & 0.9 \\
\hline \multirow[t]{4}{*}{ Education levels } & College & 175 & 21.3 \\
\hline & Bachelor & 264 & 44.4 \\
\hline & Master & 152 & 18.5 \\
\hline & Doctor & 129 & 15.7 \\
\hline \multirow[t]{4}{*}{ Years of work } & Less than 5 years & 292 & 35.6 \\
\hline & 5 less than 10 years & 231 & 28.2 \\
\hline & 10 less than 20 years & 202 & 24.6 \\
\hline & Over 20 years & 95 & 11.6 \\
\hline \multirow[t]{5}{*}{ Region } & Seoul, Gyeonggi, Incheon & 237 & 28.9 \\
\hline & $\begin{array}{l}\text { Daejeon, Sejong, } \\
\text { Chungcheong }\end{array}$ & 54 & 6.6 \\
\hline & Gwangju, Jeonla & 91 & 11.1 \\
\hline & $\begin{array}{l}\text { Daegu, Busan, Ulsan, } \\
\text { Gyeongsang }\end{array}$ & 424 & 51.7 \\
\hline & Gangwon, Jeju & 14 & 1.7 \\
\hline \multirow{7}{*}{$\begin{array}{l}\text { Type of institu- } \\
\text { tions }\end{array}$} & Clinic & 131 & 16 \\
\hline & Hospital & 361 & 44 \\
\hline & General hospital & 81 & 9.9 \\
\hline & Senior general hospital & 3 & 7.7 \\
\hline & Non-medical institution & 79 & 9.6 \\
\hline & Educational institution & 84 & 10.2 \\
\hline & Others & 21 & 2.6 \\
\hline
\end{tabular}

\section{2. 연구 도구}

본 연구에 사용된 설문지는 $\mathrm{Hong}^{6}$ 의 연구를 참고하여 물리치료사의 역할과 특성에 맞추어 수정하여 초안을 작성하였다. 작성된 초안은 물리치료학과 교수 1 명, 임상 10 년차 이상의 전문가 2 명, 대한지역사 회물리치료학회의 자문을 거쳤으며, 작성된 초안은 커뮤니티 케어에 대한 인식과 중요성 그리고 제도 내의 물리치료사의 역할(9개 항목), 커뮤니티 케어에 대한 교육 경험, 역할 수행 가능 정도(6개 항목), 제 도 내에서 물리치료 업무 수행을 위해 키워야 할 역량(5개 문항) 등으 로 구성되었다(부록 1). 일부 항목을 제외한 전체 항목들은 Likert 5 점 척도를 사용하였다. '전혀 그렇지 않다' 1 점부터 '매우 그렇다' 5 점으로 구성되었다. 초안을 바탕으로 사전 조사를 실시하여 얻은 설문지 초 안의 신뢰도를 분석한 결과, 커뮤니티케어 내에서 물리치료사의 역 할에 대한 질문의 신뢰도를 나타내는 Cronbach's alpha는 0.933 이었고, 커뮤니티케어 내에서 물리치료사로서 역할 수행 가능 정도에 대한 질문의 신뢰도를 나타내는 Cronbach's alpha는 0.866 이었다. 사전 조 
사를 바탕으로 신뢰도를 높이기 위해 설문지 항목에 대한 설명을 일 부 수정과 보완하여 본 설문을 실시하였고, 최종 설문 종료 후 신뢰도 를 분석한 결과, 물리치료사의 역할에 대한 Cronbach alpha는 0.928 , 역할 수행 가능 정도에 대한 Cronbach alpha는 0.942 이었다.

\section{3. 자료 분석}

본 연구에서 수집된 자료는 SPSS Windows 22.0을 사용하여 분석하 였다. 본 연구에 참여한 대상자의 일반적인 특성, 커뮤니티케어 제도 에 대한 물리치료사의 인식, 중요도, 교육 경험 및 수행 가능 정도와 역할에 대한 빈도 분석을 실시하고 백분율을 산출하였다. 교육 유무 에 따른 중요도와 수행 가능 정도를 보기 위해서 독립 표본 $\mathrm{t}$ 검정을 실시하였다. 학력과 임상 경력에 따른 중요도와 수행 가능 정도를 보 기 위해서 일원배치분산분석을 실시하였고, 사후검정으로 LSD 분석 방법을 시행하였다. 유의수준 $\mathrm{p}$ 값은 0.05 로 설정하였다.

\section{결 과}

\section{1. 커뮤니티케어제도에 대한 인식도}

인식도 6 문항 중 커뮤니티케어제도에 대한 인식에 대한 문항은 2.8.1 \pm 1.19 점, 커뮤니티케어제도의 중요도는 $4.19 \pm 0.90$ 점, 커뮤니티케어제

Table 2. Physical Therapist's Awareness in the community care system

$N=820$

\begin{tabular}{ll}
\hline \multicolumn{2}{c}{ Category } \\
\hline The Importance of Community Care & $4.19 \pm 0.90$ \\
Role of an physical therapist in Community Care & $4.45 \pm 0.81$ \\
Performance of Community care & $3.99 \pm 0.93$ \\
\hline
\end{tabular}

Unit $=$ score, ${ }^{+}$Mean \pm SD.

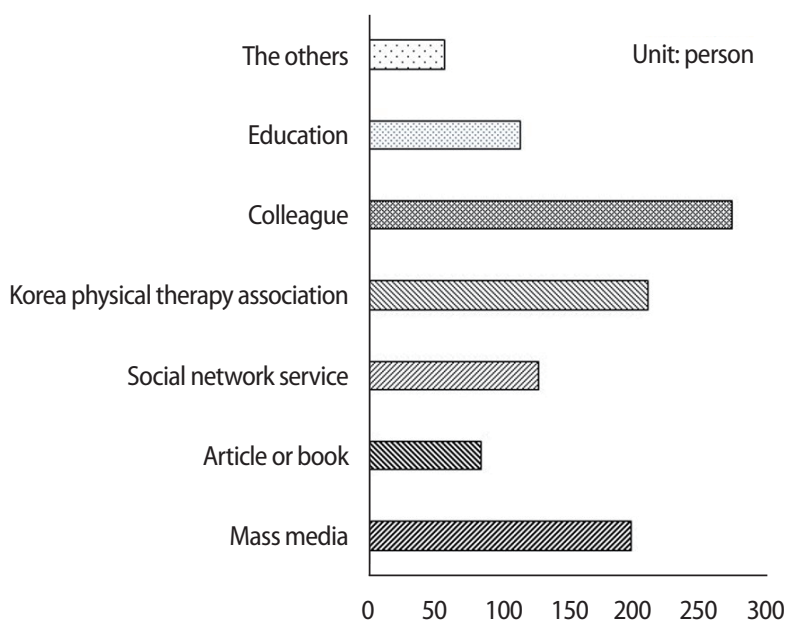

Figure 1. Sources from which participants get the information about the community care system.
도 내 물리치료사 역할의 중요도는 $4.45 \pm 0.81$ 점, 현재 커뮤니티케어 가 시행되면 가능한 수행도는 $3.99 \pm 0.93$ 점으로 나타났다(Table 2). 커 뮤니티케어제도에 대해 알게 된 경로에 대해 복수응답으로 답하도록 질문한 결과, 기사나 지인 274명(33.41\%), 대한물리치료사협회 210 명 (25.61\%), 언론매체 198명(24.15\%), SNS 128명(15.61\%), 교육 114명(13.90\%), 논문 및 도서 85 명(10.37\%), 기타 57명(6.95\%) 순이었다(Figure 1). 커뮤니 티케어에 대한 교육을 받은 경험 유무에 대한 응답은 185 명(22.56\%)이 교육을 받았고, 635명(77.44\%)이 교육을 받지 않았다(Figure 2).

\section{2. 커뮤니티케어제도 내 물리치료사의 직무 중요도 및 수행 가능 여부} 커뮤니티케어제도 내에서 중요한 물리치료사의 역할은 낙상예방훈

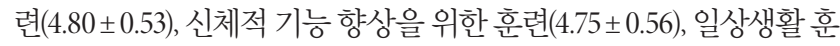

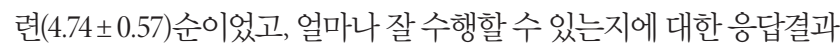

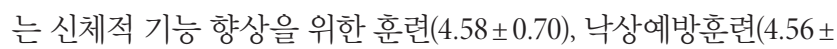

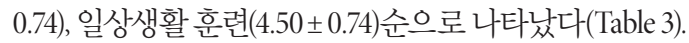

\section{3. 커뮤니티케어 교육 유무에 따른 중요도와 수행도 차이}

커뮤니티케어 교육 유무에 따른 중요도는 교육 받은 대상자 $(43.00 \pm$ $3.06)$ 가 교육을 받지 않은 대상자(41.66 4.84)보다 높게 나타났으며, 통계학적으로 유의한 차이가 있었다 $(\mathrm{p}<0.05)$. 커뮤니티케어 교육 유 무에 따른 수행도는 교육 받은 대상자(40.71 \pm 5.38$)$ 가 교육을 받지 않 은 대상자(38.43 \pm 6.45$)$ 보다 높게 나타났으며, 통계학적으로 유의한 차이가 있었다 $(\mathrm{p}<0.05)($ Table 4$)$.

\section{4. 학력과 임상 경력에 따른 중요도와 수행도 차이}

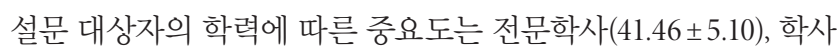
(41.67 \pm 4.94$)$, 석사 $(42.49 \pm 3.55)$, 박사 $(42.86 \pm 3.16)$ 순으로 높게 나타났 으며, 통계학적으로 유의한 차이가 있었다 $(\mathrm{p}<0.05)$. 설문 대상자의 학

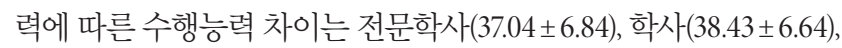

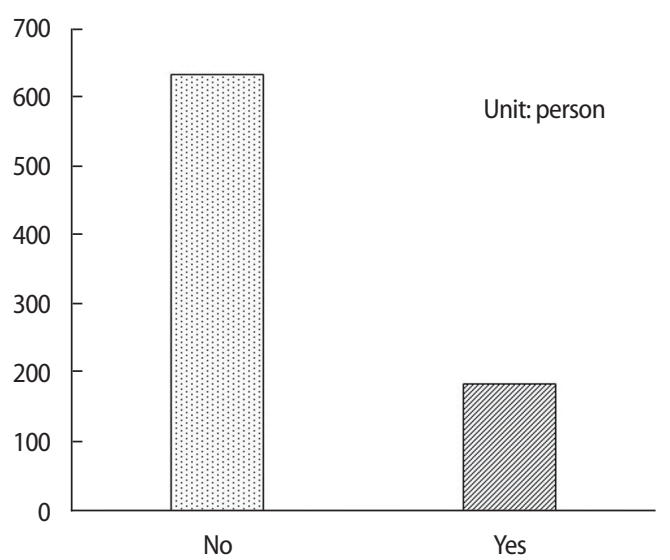

Figure 2. Education status about the community care system. 
석사 $(40.15 \pm 5.36)$, 박사(41.56 \pm 4.10$)$ 순으로 높게 나타났으며, 통계학 적으로 유의한 차이가 있었다 $(\mathrm{p}<0.05)($ Table 5$)$.

설문 대상자의 임상 경력에 따른 중요도는 5 년 이하(41.44 \pm 5.10$), 20$

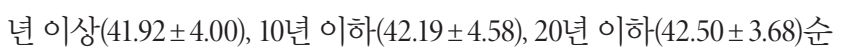
으로 나타났으며, 통계학적으로 유의한 차이가 없었다 $(\mathrm{p}>0.05)$. 설문 대상자의 임상 경력에 따른 수행능력의 차이는 5 년 이하( $37.81 \pm 6.89)$, 10 년 이하(39.46 \pm 5.92$), 20$ 년 이하(39.67 \pm 5.94$), 20$ 년 이상(39.64 \pm 5.56$)$ 순으로 나타났으며, 통계학적으로 유의한 차이가 있었다 $(\mathrm{p}<0.05)$ (Table 6).

\section{5. 커뮤니티케어제도를 물리치료사가 수행하기 위해 키워야 할 역량} 물리치료사에게 필요로 하는 키워야 할 역량으로 물리치료사의 역

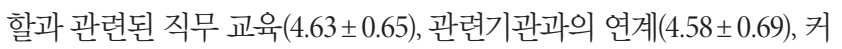

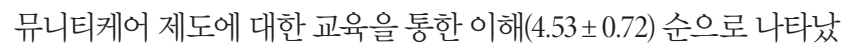
다(Table 7).

\section{고 찰}

세계적인 고령화 저출산, 가족 구조의 변화 및 인구학적, 사회경제학 적인 요인으로 지역사회중심의 돌봄 체계를 구축하고 있다. ${ }^{7} 2019$ 년

Table 4. Role priority and performance ability by the education status about the community care system

\begin{tabular}{lcccc}
\hline & $\begin{array}{c}\text { Trained } \\
(\mathrm{n}=185)\end{array}$ & $\begin{array}{c}\text { None-Trained } \\
(\mathrm{n}=635)\end{array}$ & $\mathrm{t}$ & $\mathrm{p}$ \\
\hline Priority & $43.00 \pm 3.06^{+}$ & $41.66 \pm 4.84$ & 4.52 & $0.01^{*}$ \\
Performance ability & $40.71 \pm 5.38$ & $38.43 \pm 6.45$ & 4.84 & $0.01^{*}$ \\
\hline
\end{tabular}

Unit=score, ${ }^{+}$Mean \pm SD, ${ }^{*} p<0.05$.

Table 3. Priority and Performance ability of Physical Therapists in Community Care System

\begin{tabular}{|c|c|c|c|c|}
\hline Category & Priority & Rank & Performance ability & Rank \\
\hline Activities daily living training & $4.74 \pm 0.57^{+}$ & 3 & $4.50 \pm 0.74$ & 3 \\
\hline Training to improve physical function & $4.75 \pm 0.56$ & 2 & $4.58 \pm 0.70$ & 1 \\
\hline Training for the use and management of welfare equipment & $4.66 \pm 0.62$ & 5 & $4.45 \pm 0.80$ & 4 \\
\hline Improvement of living environment suitable for the function of the target person & $4.61 \pm 0.70$ & 7 & $4.08 \pm 1.00$ & 9 \\
\hline Fall prevention training & $4.80 \pm 0.53$ & 1 & $4.56 \pm 0.74$ & 2 \\
\hline Early screening of the risk of the subject & $4.60 \pm 0.69$ & 8 & $4.16 \pm 0.94$ & 7 \\
\hline Inducing the participants' social participation & $4.56 \pm 0.72$ & 9 & $4.13 \pm 0.95$ & 8 \\
\hline Home training program development and application & $4.67 \pm 0.64$ & 4 & $4.32 \pm 0.86$ & 5 \\
\hline Health Maintenance Prevention Training & $4.61 \pm 0.68$ & 6 & $4.21 \pm 0.89$ & 6 \\
\hline
\end{tabular}

Unit=score, ${ }^{+}$Mean \pm SD.

Table 5. Role priority and performance ability by the education levels about the community care system

\begin{tabular}{|c|c|c|c|c|c|c|}
\hline & College & Bachelor & Master & Doctor & $F$ & $\mathrm{p}$ \\
\hline Role priority & $41.46 \pm 5.10^{+a}$ & $41.67 \pm 4.94^{\mathrm{a}}$ & $42.49 \pm 3.55^{b}$ & $42.86 \pm 3.16^{b}$ & 3.65 & $0.01^{*}$ \\
\hline Performance ability & $37.04 \pm 6.84 a^{a}$ & $38.43 \pm 6.64^{b}$ & $40.15 \pm 5.36$ & $41.56 \pm 4.10^{c}$ & 16.3 & $0.01^{*}$ \\
\hline
\end{tabular}

Unit $=$ score, ${ }^{+}$Mean $\pm S D,{ }^{*} p<0.05$, The different superscripts $(a, b, c)$ indicate significant differences.

Table 6. Role priority and performance ability by the clinical experience about the community care system

\begin{tabular}{lcccc}
\hline & 5 years or less & 10 years or less & 20 years or less & More than 20 years \\
\hline Importance & $41.44 \pm 5.10^{+}$ & $42.19 \pm 4.58$ & $42.50 \pm 3.68$ & $41.92 \pm 4.00$ \\
Performance & $37.81 \pm 6.89^{\mathrm{a}}$ & $39.46 \pm 5.92^{\mathrm{b}}$ & $39.67 \pm 5.94^{\mathrm{b}}$ & 3.61 \\
\hline
\end{tabular}

Unit $=$ score, ${ }^{+}$Mean $\pm S D,{ }^{*} p<0.05$, The different superscripts $(a, b)$ indicate significant differences.

Table 7. Essential skills required by Physical Therapists in Community Care System

\begin{tabular}{lllc}
\hline & \multicolumn{1}{c}{ Category } & Mean \pm SD & Rank \\
\hline Essential skills & Relationships with related institutions & $4.58 \pm 0.69$ & 2 \\
& Paper work (Preparing proposals and reports) & $4.24 \pm 0.85$ & 4 \\
& Understanding of the community care system throughout education programs & $4.53 \pm 0.72$ \\
& Job training regarding the role of physical therapists & $4.63 \pm 0.65$ \\
\hline
\end{tabular}

Unit $=$ score. 
보건복지부는 우리나라에서도 돌봄을 필요로 하는 취약층을 중심 으로 지역사회와 함께 어울려 살아가는 지역 주도형 사회정책 서비 스를 제공하기 위해 돌봄 체계를 커뮤니티케어로 전환하는 방향으 로 발표하였다. 이러한 커뮤니티케어제도에서 재활 분야는 중요한 요 소 중의 하나이다. 세계물리치료연맹(World Confederation for Physical Therapy, WCPT)은 취약층의 신체적, 정신적, 사회적 능력을 최대화 하는 수단으로 커뮤니티케어를 지지하고 있으며 이를 물리치료사가 인식하고 있어야 한다고 하였다. 커뮤니티케어의 서비스 제공은 의 사, 간호사, 물리치료사, 작업치료사, 언어치료사, 사회복지사 등과 같 이 이에 대한 전문 교육을 받은 인력들이 팀을 이루어 서비스가 필요 한 대상자 들에게 다양한 형태의 도움을 제공해 준다. ${ }^{9}$ 커뮤니티케어 를 위한 팀 구성원의 일부인 물리치료사는 대부분의 유럽 국가에서 전문 교육과정을 통해 환자의 평가, 진단, 치료 및 퇴원을 위한 의사결 정에 참여한다. 또한 일부 국가의 경우 숙련된 물리치료사가 주사를 투여하거나 특정 약물을 처방할 권한 또한 갖고 있는 경우도 있다. ${ }^{10}$ 따라서 물리치료사는 커뮤니티케어 내 다양한 형태의 서비스를 제 공하는 역할을 수행하고 이를 커뮤니티 물리치료(Community physiotherapy)라 부른다. 아직 국내에는 커뮤니티케어 관련 정책이 본격 적으로 시행되지 않았으나 국내 물리치료사들을 대상으로 노인 커 뮤니티케어 제도 내에서 물리치료사의 업무 중요도와 수행 능력에 대한 인식도를 조사하여 향후 제도의 시행에 앞서 물리치료사 전문 성 강화를 위한 자료를 제공하고자 실시하였다.

커뮤니티케어에 대한 인식도 조사 결과, 국내 물리치료사의 커뮤니 티케어제도에 대한 인식도(2.81 \pm 1.19$)$ 는 낮았으나, 제도의 시행 시 물 리치료사의 수행 정도 $(3.99 \pm 0.93)$ 는 상대적으로 높게 나타났다. 또한 커뮤니티케어에 대한 중요성 $(4.19 \pm 0.09)$ 과 제도 내에서 물리치료사 의 역할 $(4.45 \pm 0.81)$ 에 대해서 높게 인식하고 있다고 하였다. 이러한 결 과를 종합하면 국내 물리치료사의 커뮤니티케어제도에 대한 인식은 아직 기대에 미치지 못하나 제도가 시행될 경우 물리치료사의 업무 는 매우 중요하며 이를 수행할 수 있을 것으로 생각된다. 물리치료사 와 함께 재활 분야에 핵심 전문 인력인 작업치료사를 대상으로 한 커 뮤니티케어에 대한 인식도와 중요도를 조사한 $\mathrm{Hong}^{6}$ 의 연구와 유사 한 결과를 보였으며 이는 커뮤니티케어에 대한 교육 이수 유-무와 깊 은 관계를 보이는 것으로 생각된다. 본 연구의 대상자들의 커뮤니티 케어에 대한 교육 이수 유무를 묻는 설문에서 교육을 받은 물리치료 사는 전체 대상자의 $22.56 \%$ 로 매우 낮게 나타났으며 이러한 결과가 국내 물리치료사의 커뮤니티케어 인식도에 영향을 미쳤을 것으로 생 각된다.

커뮤니티케어제도 내 물리치료사의 업무 중요도에 대한 조사 결 과, 낙상 예방 $(4.80 \pm 0.53)$, 신체적 기능 향상 $(4.75 \pm 0.56)$, 일상생활동작 훈련 $(4.74 \pm 0.57)$ 순으로 나타났다. 65 세 이상의 노인의 $1 / 3$ 이상이 매
년 1회 이상의 낙상의 경험이 있고, 이런 낙상은 노인의 외상으로 인 한 입원의 절반 이상을 차지하고 있다. 이런 낙상은 주거환경 개선이 나, 운동을 통해서 예방 할 수 있다." 커뮤니티케어제도의 서비스 대 상자가 노인임을 고려하였을 때, 특히 낙상 예방은 물리치료사가 수 행할 수 있는 가장 중요한 요소로 인식하고 있는 것으로 사료된다.

커뮤니티케어제도 내 물리치료사로서 현재 수행 가능한 업무능력 에 대한 조사 결과, 신체적 기능 향상 $(4.58 \pm 0.70)$, 낙상 예방 $(4.56 \pm$

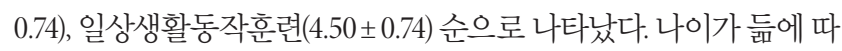
라 신체 능력이 저하되고, 만성 질환에 노출될 확률이 높아진다. 따라 서 신체적 기능 향상은 신체 활동량을 증진시키고, 만성 질환의 예방 및 사망의 위험을 감소시킬 수 있다.12 이런 신체적 기능 향상에 관한 업무는 특히 임상 물리치료사의 현장에서 주로 하는 업무로써, 물리 치료사가 가장 적절히 수행 가능한 것으로 사료된다.

설문 대상자의 일반적인 특성을 기준으로 평가하는 자료에 의하 면, 교육을 받은 대상자가 교육을 받지 않은 대상자 보다 커뮤니티케 어가 중요하다고 생각하고, 또한 커뮤니티케어 교육을 받은 대상자가 수행도 부분도 높게 나타났다. 또한 설문대상자의 학력에 따른 커뮤 니티케어에 대한 중요도와 수행능력의 차이는 학력이 높을수록 커 뮤니티케어를 보다 중요하게 인식하고, 해당 서비스를 수행 가능하다 고 인식하고 있다. 이는 교육을 통해서 커뮤니티케어 내의 물리치료 사의 역할을 보다 정확히 이해하고, 그 중요성을 인식하고 있다고 생 각할 수 있으며, 또한 교육을 통하여 커뮤니티케어 내에서 물리치료 사가 행할 수 있는 역할 범위를 정확히 파악하여, 그 역할을 충분히 수행 가능하다는 인식에 영향을 미쳤을 것으로 사료된다.

설문 대상자의 임상 경력에 따른 커뮤니티케어에 대한 중요도 인 식은 임상 경력에 상관없이 모두 중요하게 인식하고 있으며, 그 수행 능력은 임상 경력 5년 미만의 치료사보다 5년 이상의 치료사가 그 수 행능력이 뛰어난 것으로 조사되었고, 임상 경력 5년 이상이 넘어가면 임상경력에 따른 수행능력의 차이는 없는 것으로 조사되었다. 또한 물리치료사에게 필요한 중요한 역량으로 물리치료사의 역할과 관련 된 직무 교육이 가장 높게 조사되었다. 이는 향후 임상 경력이 낮은 신 입 물리치료사를 위한 커뮤니티케어 관련 직무 교육이 필요하고, 성 공적인 커뮤니티케어의 국내 정착을 위해서는 대한물리치료사협회, 임상 학회 등의 다양한 학제 간 전문가적 협력을 중심으로 보건당국 과 협의하여 실제 커뮤니티케어 내 제도에서 물리치료사의 직무범위 를 보다 명확히 하고, 이를 대학 교육제도 내에서 충분히 교육을 할 수 있는 제도를 만들어야 할 것으로 사료된다.

유럽에서의 커뮤니티케어에 대한 법률적 정의는 일반적으로 지역 사회 서비스 기관에서 제공하는 사회적 돌봄 서비스 의미한다. 즉 사 회 서비스 책임을 가진 지방 자치구와 의사결정을 하는 지방의회가 그 역할을 조정한다. ${ }^{13}$ 커뮤니티케어는 유럽에서 지난 60 년동안 계속 
확장되어 현재 다양한 법률제정으로 구성되어 있다. 여기에는 요양 원의 주거, 요양 돌봄, 가정에서의 개인 돌봄, 휴일 돌봄과 같은 서비 스뿐만 아니라 사람들의 일상 생활에 도움을 줄수 있는 장비의 제공 과 집안 환경 개선사업, 주간보호센터, 레크리에이션 활동 등이 포함 된다. ${ }^{14}$ 이런 커뮤니티케어는 인구의 노령화가 높은 일본에서 지역포 괄케어 시스템으로 불려지며, 이 시스템은 중앙부처에서 정책을 정하 고 보조금을 지원하여 정책을 실행하는 구조가 아닌, 해당 지역의 특 성에 맞는 의료복지를 제공하고자 하는 지역 사회 중심의 고령자 지 원 시스템이다. ${ }^{15}$ 일본과 한국은 인구의 고령화 추세에 따른 사회적 변화가 상당히 유사한 점을 지니고 있으며, 특히 물리치료 분야는 의 료적, 교육적 측면에서 상당히 유사한 점을 지니고 있다. ${ }^{16}$ 따라서 한 국의 인구 고령화에 따른 커뮤니티케어의 도입에 있어 일본의 사회적 동향과, 의료적 그리고 교육적 변화를 이해할 필요가 있다.

본 연구의 결과와 같이 임상 경험에 따른 수행력의 차이에 따라 교 육의 필요성이 제기되고, 이와 같은 교육의 필요성을 준비하기 위해 서 이미 시행된 일본의 커뮤니티케어에서 물리치료사의 역할과 중요 성을 파악하고, 이를 준비할 수 있는 교육 및 필요한 업무 능력에 대 하여 논의할 필요성이 있다고 사료된다. 또한 본 연구는 전국 물리치 료사를 대상으로 커뮤니티케어에 관련하여 조사를 실시하였지만, 지 역의 분포가 전국 믈리치료사 분포도와 일부 상이했다. 따라서 추후 연구에서는 전국 단위의 협회 및 학회를 주축으로 조사를 실시하여, 보다 다양한 지역의 대상자를 통해서 조사가 이루어져야 할 것으로 사료된다. 향후 연구에서는 해외 사례를 통한 커뮤니티케어에서의 물리치료사의 역할과 직무 능력에 대해서 보다 폭넓은 연구가 이루 어져 노인의 커뮤니티케어의 시행에 있어 국내 실정에 맞는 정책이 시 행될 수 있도록, 기초조사가 필요할 것으로 사료된다.

\section{ACKNOWLEDGEMENTS}

본 연구는 대한물리치료사협회 부산광역시회의 물리치료 정책에 관 한 연구의 연구비 지원을 받았음.

\section{REFERENCES}

1. Ministry of Health and Welfare. Community care promotion direction for community-based welfare implementation. 2018.

2. You JM. A Comparative Analysis of Care Management System in LongTerm Care for the Elderly in UK Germany and Australia. KJGSW. 2009:43(1)381-406.

3. Patricia CR. Policy design and its results: an analysis on the effect of decentralization on the performance of Pennsylvania's child welfare service delivery system. The Pennsylvania State University. Dissertation of Doctorate Degree. 2004.

4. Webster IW. Physiotherapy and community medicine. Aust J Physiother. 1980;26(2):45-54.

5. Yoon TH, Kim YS, Kim HR. Home-based Physical Therapy Infrastructure and the Direction of Policy Development for Long Term Care Insurance in Community. J Phys Ther Sci. 2008;15(2):61-9.

6. Hong SY. Awareness of the Job Task Importance and Performance of Occupational Therapists in the Elderly Community Care System. JKCBOT. 2019;9(3):11-9.

7. Park JS. Development of Social Care and Community Care Legislations and Mixed Economy of Welfare in the UK. Korean Academy of Social Welfare and Law. 2018;9(3):181-207.

8. Korea Institute of Physical Therapy Policy. Community-basedphysical therapy 2nd edition. Seoul, Hyunmoonsa, 2020:4-11.

9. Means R, Richards S, Smith R. Community care: Policy and practice. New York, Palgrave Macmillan, 2008:121-30.

10. Long J. European region of the WCPT statement on physiotherapy in primary care. Prim Health Care Res Dev. 2019;4(20):e147.

11. Sherrington C, Whitney JC, Lord SR et al. Effective exercise for the prevention of falls: a systematic review and meta-analysis. J Am Geriatr Soc. 2008;56(12):2234-43.

12. Warburton DER, Nicol CW, Bredin SSD. Health benefits of physical activity: the evidence. CMAJ. 2006;174(6):801-9.

13. Mandelstam M. Community care practice and the law. 3rd ed. London, Jessica Kingsley Pub, 2005:1237.

14. Mandelstam M. Quick Guide to Community Care Practice and the Law. London, Jessica Kingsley Pub, 2010:12-8.

15. Niki T. Community Care of Japan. Seoul, Bookmarker, 2018:12-22.

16. Lee HY, Park RJ, Kim JS, et al. Study on the Japanese Home Care Service. J Kor Phys Ther. 2000;12(1):113-8. 